\title{
Effects of albinism on copulatory behavior and sperm competition in prairie voles (Microtus ochrogaster)
}

\author{
DONALD A. DEWSBURY and SUSAN E. WARD \\ University of Florida, Gainesville, Florida
}

\begin{abstract}
Three studies of copulatory behavior and sperm competition in albino and wild-type prairie voles, Microtus ochrogaster, were completed. In Experiment 1, albino males had shorter interintromission intervals than wild-type males when mating with hormone-injected females. In Experiment 2 , sperm competition was studied using a reconstituted albino line in which the albino gene was placed on a background of predominately wild type. There were no significant genotype effects on copulatory behavior, although there was an effect of mating order. The previously demonstrated advantages of albino males and of males mating last were replicated. In Experiment 3, the albino males' advantage could not be overcome even when the wild-type males were permitted two ejaculations to their one. Albinism in prairie voles appears to have a strong effect on fertilizing capacity but to have only weak effects on behavior.
\end{abstract}

The purpose of this research was to study the effect of the albino gene, or genes linked to the albino gene, on copulatory behavior and sperm competition in prairie voles, Microtus ochrogaster. Analysis of single-gene effects can provide insight into the genetic influences and development of behavior (e.g., Thiessen, 1971). The gene for albinism in house mice has received much attention in behavioral studies (reviewed by Wilcock, 1969). For example, albinism has been shown to affect both avoidance learning (Winston, Lindzey, \& Connor, 1967) and open-field behavior (DeFries, 1969). Although important, such effects can be a product of gene-environment interactions (e.g., McReynolds, Weir, \& DeFries, 1967) and can be very difficult to separate from effects of genes linked to the albino gene (Wilcock, 1969).

Parameters of rodent copulatory behavior are sensitive to differences in genotype (e.g., Dewsbury, 1975; Dewsbury, Oglesby, Shea, \& Connor, 1979). Prairie voles copulate reliably in the laboratory (Gray \& Dewsbury, 1973), and a recessive albino mutant has been isolated (Richmond \& Conaway, 1969). In a study of sperm competition in albino and wild-type voles, Dewsbury and Baumgardner (1981) found that albino males had significantly higher mount frequencies that wild-type males. In addition, the albinos had greater differential fertilizing capacity-the capacity to gain representation in litters resulting from multiple-male mating with a single female when such factors as the order, timing, and number of ejaculations by the two males are controlled. Both factors are explored further in the present research.

This research was supported by Grant BNS82-00689 from the National Science Foundation. We thank Agnes Newcomer for her help in conducting Experiment 1. The first author is with the Department of Psychology, University of Florida, Gainesville, FL 32611; the second author is now with the Department of Psychology, Mercer University, Atlanta, GA 30341.

\section{EXPERIMENT 1}

The first experiment was designed to analyze copulatory behavior in a standard test situation, uncomplicated by multiple-male mating and the sperm-competition situation.

\section{Method}

The subjects were 10 male albino prairie voles, Microtus ochrogaster, 10 wild-type males, and 20 female albino voles from the colonies maintained at the University of Florida. All were at least 90 days of age and without prior copulatory experience at the start of testing. They were kept on a reversed 16-h-light:8-h-dark photoperiod.

Male-female pairs of voles received repeated tests of copulatory behavior, spaced at least 2 weeks apart, until three tests with copulation were completed. Tests were conducted $2-4 \mathrm{~h}$ after light offset in neutral test cages measuring $48 \times 27 \times 13 \mathrm{~cm}$. The animals were preadapted to the test cages prior to the initial testing day. On each test day, males were permitted $15 \mathrm{~min}$ in the test cage prior to introduction of the female. If a male failed to achieve intromission within $30 \mathrm{~min}$ of introduction of the female, the test was discontinued and discounted. If copulation did occur, the test was continued until attainment of a standard satiety criterion of $30 \mathrm{~min}$ with no copulations. Behavioral events were recorded on an Esterline-Angus operations recorder supplemented with handwritten tallies. Females were brought into estrus with injections of $.06 \mathrm{mg}$ of estradiol benzoate 72 and $48 \mathrm{~h}$ before testing and $.6 \mathrm{mg}$ of progesterone $4 \mathrm{~h}$ before testing.

Copulatory behavior in prairie voles consists of three primary classes of events: mounts (with no vaginal insertion), intromissions (mounts with vaginal insertion-generally with repetitive thrusting during the mount), and ejaculations (mounts with insertion and semen emission). These events are organized into ejaculatory series, with each series beginning with an intromission and ending with an ejaculation. The following standard measures (see Dewsbury \& Baumgardner, 1981, and Gray \& Dewsbury, 1973) were used: mount latency (ML), intromission latency (IL), ejaculation frequency (EF), ejaculation latency (EL), intromission frequency (IF), mount frequency (MF), thrust frequency (TF), ejaculatory thrust frequency (ET), thrusts per intromission (T/I), mean intromission duration (MID), and mean interintromission interval (MIII). All temporal measures were in seconds; in cases in which a measure refers to a particular series, that series is designated (e.g., IF-2). 
Table 1

Measures of Copulatory Behavior in Albino and Wild-Type Prairie Voles in Hormone-Induced Estrus in Experiment 1

\begin{tabular}{lrrc}
\hline & \multicolumn{2}{c}{ Mean } & \\
\cline { 2 - 3 } Measure & Wild & Albino & $\mathrm{F}(1,15)$ \\
\hline EF & 2.3 & 2.7 & 1.10 \\
ML & 137.1 & 127.1 & 0.13 \\
IL & 254.1 & 167.5 & 1.86 \\
EL-1 & 254.1 & 329.6 & 0.52 \\
IF-1 & 8.7 & 17.5 & 2.62 \\
MF-1 & 8.3 & 8.4 & 0.00 \\
TF-1 & 35.4 & 54.2 & 2.91 \\
ET-1 & 4.9 & 4.6 & 0.21 \\
MIII-1 & 21.9 & 10.3 & $8.82 *$ \\
\hline
\end{tabular}

${ }^{*} p<.01$.

\section{Results and Discussion}

Measures of copulatory behavior are presented in Table 1. There was one significant difference: Wild-type males had significantly longer MIIIs in the first series than did albino voles.

The difference in MF, found in sperm-competition tests by Dewsbury and Baumgardner (1981), was not found in this study. The difference in MIII, found in the present study, was not found by Dewsbury and Baumgardner. Thus, these strain differences in prairie voles are either unreliable or quite situation dependent.

\section{EXPERIMENT 2}

Because the albino and wild-type animals originated from different stocks, it is impossible to attribute betweenstrain differences to the albino locus per se. Therefore, in Experiment 2, the lines were cross-bred to place the albino gene on a background more similar to that of the wild-type animals.

\section{Method}

Male and female albino and wild-type voles were crossbred to produce an $F_{1}$ generation. These animals were bred among themselves to produce an $F_{2}$ generation. Albino animals from the latter generation were backcrossed to wild stock. Animals from the resulting generation were bred among themselves, and albino offspring resulting from such matings were chosen as the progenitors of the reconstituted albino line. The albino gene, then, was on a background that was, on average, $75 \%$ of the wild-type.

The subjects for Experiment 2 were 16 wild-type males and 17 males and 21 females from the reconstituted albino line. Details were as in Experiment 1 .

Testing procedures were the same as those of Dewsbury and Baumgardner (1981). In order to stimulate them into natural estrus, females were housed in a divided cage across a barrier from a male. Daily vaginal smears were taken. Estrous females were mated sequentially to two males, one of each genotype, for one ejaculatory series each. Tests were in neutral test cages. The female was first placed in a cage with a male of the genotype opposite to that of the male that had stimulated her into estrus. After the pair had completed an ejaculatory series, she was moved to a cage with the male that had induced her into estrus. If either male failed to copulate, the female was generally tried with a second male of the appropriate genotype. After having received an ejaculation from the second male, the female was returned to her home cage, along with bedding from the divided cage in which estrus had been induced. Behavioral measures were determined, and litter composition was recorded on the day of birth.

Each female received two tests, one mating with males in each order. Nine females completed tests in the albino-first, wild-first order, and 12 females in the wild-first, albino-first order.

\section{Results and Discussion}

Data relating to litter composition for both the present study and that of Dewsbury and Baumgardner (1981) are compared in Table 2. Data from the two studies are quite similar. In all conditions, the majority of pups born were albino. Looking within condition, albino males sired significantly more offspring in the wild-first but not in the albino-first tests. Chi-square tests revealed a significant difference between conditions (i.e., as a function of mating order) in both studies; the difference is significant in the previous study only if Wilcoxon tests are used. It appears that crossbreeding had little effect on differential fertilizing capacity.

The first two tests in each condition for 10 males of each genotype were used in three-way repeated-measures analyses of variance, with mating order, test, and genotype as main effects. Results for selected measures are presented in Table 3. There were no significant effects of genotype. The genotype difference for MIII-1 was in the same direction as the significant effect in Experiment 1; that for MF-1 was in the direction opposite to that found by Dewsbury and Baumgardner (1981). There were two significant effects of mating order. Like deer mice but unlike voles in the previous work, males had shorter mount and intromission latencies when mating second with a female than when mating first.

Table 2

Comparison of Sperm-Competition Data From Studies of Original and Reconstituted Albino Versus Wild-Type Prairie Voles

\begin{tabular}{|c|c|c|c|c|}
\hline \multirow[b]{2}{*}{ Measure } & \multicolumn{2}{|c|}{ Original } & \multicolumn{2}{|c|}{ Reconstituted } \\
\hline & Albino 1st & Wild 1st & Albino 1st & Wild 1st \\
\hline Number of litters & 21 & 21 & 21 & 21 \\
\hline Number of pups & 78 & 87 & 68 & 48 \\
\hline Percentage of pups albino & 56 & 88 & 59 & 83 \\
\hline Binomial within condition & 0.56 & $7.08 * *$ & 1.33 & $4.48 * *$ \\
\hline Wilcoxon between conditions & \multirow{2}{*}{\multicolumn{2}{|c|}{$\begin{array}{c}1 * \\
22.88^{* *}\end{array}$}} & \multirow{2}{*}{\multicolumn{2}{|c|}{$\begin{array}{l}24.5 \\
6.79 *\end{array}$}} \\
\hline$\chi^{2}$ between conditions & & & & \\
\hline
\end{tabular}

Note- "Original" data are based on Dewsbury and Baumgardner (1981).

${ }^{*} p<.01 . \quad *_{p}<.001$ 
Table 3

Selected Measures of Copulatory Behavior in Experiment 2

\begin{tabular}{|c|c|c|c|c|c|c|}
\hline \multirow[b]{2}{*}{ Measure } & \multicolumn{2}{|c|}{$\begin{array}{l}\text { Mean by } \\
\text { Genotype }\end{array}$} & \multicolumn{2}{|c|}{$\begin{array}{c}\text { Genotype } \\
\text { Effect }\end{array}$} & \multicolumn{2}{|c|}{$\begin{array}{c}\text { Mating } \\
\text { Order Effect }\end{array}$} \\
\hline & Wild & Albino & $F(1,18)$ & $\mathrm{p}$ & $F(1,18)$ & $\mathrm{p}$ \\
\hline ML & 105.4 & 88.8 & 0.44 & n.s. & 5.14 & .04 \\
\hline IL & 160.8 & 111.1 & 1.56 & n.s. & 4.84 & .04 \\
\hline MF-1 & 11.0 & 6.9 & 2.86 & .11 & 0.56 & n.s. \\
\hline MIII-1 & 34.6 & 24.3 & 2.44 & .14 & 0.31 & n.s. \\
\hline
\end{tabular}

\section{EXPERIMENT 3}

It was clear from Experiment 2 that even reconstituted albino male prairie voles have an advantage over wildtype males with respect to differential fertilizing capacity. In deer mice, laboratory rats, and hamsters, litter composition is a function, in part, of the relative number of ejaculations attained by each of the two males (Dewsbury \& Baumgardner, 1981; Lanier, Estep, \& Dewsbury, 1979; Oglesby, Lanier, \& Dewsbury, 1981). Experiment 3 was designed to determine whether the advantage of albino males could be overcome by permitting wildtype males more ejaculations.

\section{Method}

Seventeen of the females from Experiment 2 each received one additional test using the same males and basic procedures as in Experiment 2 . In these tests, the females received two ejaculatory series from a wild-type male followed by one series with an albino male.

\section{Results and Discussion}

The 17 litters were $79 \%$ albino, with 46 albino and 12 wild-type pups. A binomial test revealed a significant advantage for the albino males $(\mathrm{z}=4.33, \mathrm{p}<.001)$. A Wilcoxon test was used to compare the percentage albino for each female in the present study with that from the wild-male-first condition in Experiment 2. The result was not significant $(\mathrm{T}=5, \mathrm{~N}=7, \mathrm{p}>.05)$. Clearly, wildtype males were at a disadvantage in gaining representation even when permitted two ejaculations to the one by albino males mating last.

\section{GENERAL DISCUSSION}

The albino locus in prairie voles appears to have but a weak effect on copulatory behavior. Albino males tend to have shorter interintromission intervals than wild-type males, but the behavioral differences are inconsistent and difficult to attribute to the albino gene per se.

In contrast, the effect of albinism on results in sperm-competition studies appears consistent. Even when two males attain equal numbers of ejaculations and the timing and order of mating are controlled or counterbalanced, albino males gain a disproportionate representation in resulting litters. This advantage held even after a "reconstituted" albino line was bred so that the albino gene was on a predominately wild-type background. Wild-type and albino males do not differ with respect to the number of sperm per ejaculate (Dewsbury \& Baumgardner, 1981). Therefore, the difference probably is the result of some constituent of the ejaculate. It is possible that the advantage may accrue only with fe- males of a given genotype; this is difficult to study, because the albino gene is genetically recessive. Clearly, use of the albino locus as a marker gene in studies of sperm competition with prairie voles is problematical.

The pattern of sperm interaction is one of the most important characters of a species in relation to the evolution of social behavior (Smith, 1984). These data replicate the earlier study in showing a last-male advantage in prairie voles-a result similar to that in many insects (Parker, 1970). Such a pattern would be expected in species in which males invest substantially via nonpromiscuous mating effort or parental effort (Gwynne, 1984). Prairie voles are such a species, displaying a monogamous system and male paternal care under at least some conditions (Getz \& Carter, 1980). Thus, the last-male advantage observed in the present study may be related to high male confidence of paternity and to the display of paternal behavior associated with male-female bonding and association during breeding activity.

\section{REFERENCES}

DeFries, J. C. (1969). Pleiotropic effects of albinism on open field behavior in mice. Nature 221, 65-66.

DewsBury, D. A. (1975). A diallel cross analysis of genetic determinants of copulatory behavior in rats. Journal of Comparative and Physiological Psychology, 88, 713-722.

Dewsbury, D. A., \& BaUmGaRDNER, D. J. (1981). Studies of sperm competition in two species of muroid rodents. Behavioral Ecology and Sociobiology, 9, 121-133.

Dewsbury, D. A., Oglesby, J. M., Shea, S. L., \& Connor, J. L. (1979). Inbreeding and copulatory behavior in house mice: A further consideration. Behavior Genetics, 9, 151-163.

Getz, L. L., \& CARTER, C. S. (1980). Social organization in Microtus ochrogaster populations. The Biologist, 62, 56-69.

Gray, G. D., \& DEwSBury, D. A. (1973). A quantitative description of copulatory behavior in prairie voles (Microtus ochrogaster). Brain, Behavior and Evolution, 8, 437-452.

GWYNNE, D. T. (1984). Male mating effort, confidence of paternity and insect sperm competition. In R. L. Smith (Ed.), Sperm competition and the evolution of animal mating systems (pp. 117-149). New York: Academic Press.

LANIER, D. L., EsteP, D. Q., \& Dewsbury, D. A. (1979). Role of prolonged copulatory behavior in facilitating reproductive success in a competitive mating situation in laboratory rats. Journal of Comparative and Physiological Psychology, 93, 781-792.

McReynolds, W. E., WeIR, M. W., \& DeFries, J. C. (1967). Openfield behavior in mice: Effect of test illumination. Psychonomic Science, 9, 277-278.

Oglesby, J. M., Lanier, D. L., \& Dewsbury, D. A. (1981). The role of prolonged copulatory behavior in facilitating reproductive success in male Syrian golden hamsters (Mesocricetus auratus) in a competitive mating situation. Behavioral Ecology and Sociobiology, 8, 47-54.

PARKer, G. A. (1970). Sperm competition and its evolutionary consequences in the insects. Biological Reviews, 45, 525-567.

Richmond, M., \& ConAWAY, C. H. (1969). Management, breeding, and reproductive performance of the vole, Microtus ochrogaster, in a laboratory colony. Laboratory Animal Care, 19, 80-87.

SMITH, R. L. (Ed.) (1984). Sperm competition and the evolution of animal mating systems. New York: Academic Press.

THIESSEN, D. D. (1971). Reply to Wilcock on gene action and behavior. Psychological Bulletin, 75, 103-105.

WiLCOCK, J. (1969). Gene action and behavior: An evaluation of major gene pleiotropism. Psychological Bulletin, 72, 1-29.

Winston, H., Lindzey, G., \& ConNor, J. (1967). Albinism and avoidance learning in mice. Journal of Comparative and Physiological Psychology, 63, 77-81.

(Manuscript received for publication September 4, 1984.) 